\title{
ROLE OF ULCER GRADING CLASSIFICATION IN PREDICTING LEVEL OF AMPUTATION IN DIABETIC FOOT ULCER.
}

1. FCPS (Surgery)

Associate Professor Surgery

Fauji Foundation Hospital,

Rawalpindi.

2. FCPS (Surgery)

Professor Surgery

Wah Medical College, Wah Cantt.

3. M.Phil

Assistant Professor Rehabilitation Islamabad Medical and Dental

College, Islamabad.

4. MD (Nephrology)

Senior Registrar

DHQ Teaching Hospital, Rawalpindi.

5. FCPS (Plastic Surgery)

Assistant Professor

Wah Medical College, Wah Cantt.

\section{Correspondence Address:}

Dr. Naveed Arshad

Department of Rehabilitation

Islamabad Medical and Dental

College, Islamabad,

Main Murree Road, Sattran Meel,

Bhara Kahu, Islamabad.

oliajann@gmail.com

Article received on:

06/01/2020

Accepted for publication:

$11 / 05 / 2020$

\begin{abstract}
Khalil ur Rehman', Muhammad Naeem Ashraf ${ }^{2}$, Naveed Arshad $^{3}$, Saima Mir $^{4}$, Nadeem Pasha
\end{abstract}
ABSTRACT... Objectives: The study was designed to analyze and predict the diabetic foot ulcer outcome in terms of either healing or progression to amputation in patients presenting with diabetic foot. Study Design: Cross Sectional study. Setting: POF Hospital Wah Cantt. Period: January 2017 to December 2017. Material \& Methods: Demographics of patients along with duration of diabetic foot ulcer and its grade according to Wagner classification were recorded. Nonprobability consecutive sampling was done for the data collection. Management of ulcer was carried out with debridement, daily dressings and appropriate antibiotic. Patients were followed over period until ulcer healed completely or amputation performed. The outcome of diabetic foot ulcer was noted to complete the study. Results: One hundred patients with mean age were $54.24 \pm 3.65$ years. Mean duration of diabetic ulcer was $17.61 \pm 4.6$ days. All patients with gradelulcer recovered completely withouttheneed ofamputation. Out of 25 patients with grade Il ulcers $13(52 \%)$ patients recovered without amputation while $12(48 \%)$ patients had minor amputation. Similarly 16 patients presenting with grade III ulcers 12 (75\%) had minor amputation while $4(25 \%)$ underwent major amputation. Out of 18 patients with grade IV ulcers, 6 $(33 \%)$ had minor amputation while $12(67 \%)$ had major amputation. All 13 patients with grade $V$ ulcer underwentmajor amputation. Relation of grades of ulcer with respect to level of amputation inside the grading classification of ulcer showed significant $(p=0.01)$. Conclusion: Healing of the diabetic foot ulcer with preservation of limb function must be a goal of treating diabetic foot. Wagner classification of diabetic foot ulcer high grade is associated with increased risk along with high level of foot amputation.

Key words: $\quad$ Amputation, Diabetic Foot, Ulcer.

Article Citation: Khalil ur Rehman, Ashraf MN, Arshad N, Mir S, Pasha N. Role of ulcer grading classification in predicting level of amputation in diabetic foot ulcer. Professional Med J 2020; 27(9):1931-1935.

DOI: 10.29309/TPMJ/2020.27.09.4465

\section{INTRODUCTION}

Diabetes mellitus (DM) is one of the most common metabolic disorders. Globally, an estimated 422 million adults were living with diabetes in 2014, compared to 108 million in $1980 .^{1}$ According to the World Health Organization, 552 million adults will have diabetes till year $2030 .^{2}$ Diabetes leads to series of complications, such as retinopathy, diabetic foot, nephropathy and cardiovascular diseases. With rising number of diabetics, the frequency of complications is expected to increase. ${ }^{3}$ The diabetic foot is one of the foremost complication estimating $10 \%$ to $25 \%$ of patients developing a diabetic foot ulcer in their lifetimes ${ }^{4}$, resulting in acute health, mortality and increasing the economic load of the disease in society. ${ }^{5}$
Recent studies showed the annual incidence of diabetic foot ulcers among diabetic patients as approximately $2 \%$, and $15 \%$ of these eventually undergo lower limb amputation. ${ }^{6}$ Additionally diabetic patients have 15-20 times higher incidence of amputation rate as compared to nondiabetic patients. ${ }^{7}$ Various studies documented the incidence of amputation in diabetic patients ranging from $5.2 \%$ to $39.4 \% .^{8}$ Different foot ulcer classification systems have been developed in an attempt to categorize ulcers more effectively and thus explain comparison of the outcome of management in different centers and treatment approaches. These are based on the site of ulcer, depth, presence of neuropathy, infection and peripheral arterial disease, and have been used 
to compare the outcomes. ${ }^{9}$ The most commonly used ulcer classification systems is Wagner Ulcer Classification System (from 0 to 5 grades), Grade 0 ; skin intact, Grade 1; superficial ulcer of skin, Grade 2; ulcers extend into tendon, bone, or capsule, Grade 3; deep ulcer with osteomyelitis or abscess, Grade 4; partial foot gangrene, Grade 5 ; whole foot gangrene. ${ }^{10}$ The aim of this study was to analyze role of ulcer grade as a predictor level of amputation in diabetic foot ulcer patients and also to identify which signs of infection independently predict amputation. It was decided to disseminate the results to the general surgeons and recommend the routine use of ulcer grading classification in various types of amputation in diabetic foot ulcers.

\section{MATERIAL \& METHODS}

This analytical cross sectional study was carried out at the emergency department (ED) and outpatient of surgical department POF Hospital Wah Cantt from January 2017 to December 2017. The research protocol was approved by the ethical committee of the hospital. Informed consent was taken from all participants. A sample of $n=100$ patients, (sample size was calculated by using the formula $n=Z^{2}{ }_{1-a / 2} \times S_{N} \times\left(1-S_{N}\right) / L^{2}$ $\times$ prevalence, whereas estimated proportion of response distribution was $0.07 \%$, desired precision of estimation of margin of error was $0.05 \%$, and confidence level was $0.95 \%$.

Both male and females, aged 18 years and above with diabetes mellitus admitted to the institution with a primary diagnosis of diabetic foot ulceration were included in the study. Diabetic patients associated with venous ulceration and infectious ulcers like tuberculosis were excluded from the study. Diabetic foot ulceration was defined as loss of continuity in epidermis of foot. The patients were followed up in OPD for 06 months at least. Patients were recruited consecutively until the target sample size was achieved. All variables were collected through a structured interview and detailed foot examination. Demographic characteristics (age at the time of inclusion, gender of patient, duration of diabetes, and sugar levels on presentation) were noted on pre-designed proforma. The severity of ulcer was determined using the Wagner Classification System. The duration of ulceration was recorded. Amputation was divided into two categories, minor lower extremity amputation and major lower extremity amputation. Minor lower extremity amputation was defined as the surgical removal of toe(s), ray or forefoot. Major lower extremity amputation was considered amputation of the entire foot by any level of the leg (including the ankle). Nonprobability consecutive sampling was done for data collection and the duration of study was over a period of one year.

All obtained data on predesigned proforma was entered on SPSS version 20. Quantitative variables were analyzed using descriptive statistics. Unless otherwise indicated, data were presented as mean \pm standard deviation. To compare the grades of ulcer with types of amputation, the quantitative variables were analyzed using chi square distribution at $0.05 \%$ level of significance.

\section{RESULTS}

Mean age of all patients was $54.24 \pm 3.65$ yrs. Minimum age was $41 \mathrm{yrs}$. and maximum age was 72 yrs. Out of 100 patients 62 patients were male and 38 patients were female. Mean duration of diabetes was $8.672 \pm 1.5 \mathrm{yrs}$. with minimum duration was 4 yrs. and maximum duration was 16 yrs. Mean blood sugar reading (MBR) at time of presentation was $275.44 \pm 67 \mathrm{mg} / \mathrm{dl}$. Minimum BSR was $165 \mathrm{mg} / \mathrm{dl}$ and maximum BSR was $479 \mathrm{mg} / \mathrm{dl}$. BSR level was categorized into two categorizes; controlled BSR level ( $<250 \mathrm{mg} /$ dl) and uncontrolled BSR level (>250 mg/dl). Controlled BSR level was found in 32 patients and uncontrolled BSR level was found in 68 patients. Mean duration of ulceration was $17.61 \pm 4.6$ days; minimum duration was 03 days and maximum duration was 37 days.

Ulcers were categorized on basis of Wagner ulcer classification at the time of presentation. 28 patients had grade I ulcers, 25 patients had grade II ulcers, 16 patients had grade III ulcer, 18 patients had grade IV ulcer and 13 patients had grade $\mathrm{V}$ ulcers. Results were categorized on basis of ulcers (Table-I). 


\begin{tabular}{|l|c|c|c|}
\hline \multicolumn{1}{|c|}{ Types of Ulcer } & No Amputation & Minor Amputation & Major Amputation \\
\hline Grade I & $28(100 \%)$ & Nil & Nil \\
\hline Grade II & $13(52 \%)$ & $12(48 \%)$ & $04(25 \%)$ \\
\hline Grade III & Nil & $12(75 \%)$ & $12(67 \%)$ \\
\hline Grade IV & Nil & $06(33 \%)$ & $13(100 \%)$ \\
\hline Grade V & Nil & Nil & \\
\hline
\end{tabular}

Table-I. Frequencies and percentages of grades of ulcer and types of amputation, $n=100$

\begin{tabular}{|l|c|c|c|c|c|c|c|}
\hline $\begin{array}{c}\text { Types of } \\
\text { Ulcer }\end{array}$ & $\begin{array}{c}\text { No } \\
\text { Amputation }\end{array}$ & $\begin{array}{c}\text { Minor } \\
\text { Amputation }\end{array}$ & $\begin{array}{c}\text { Major } \\
\text { Amputation }\end{array}$ & Total & $\begin{array}{c}\text { Chi Square } \\
\text { Value }\end{array}$ & $\begin{array}{c}\text { Crit. } \\
\text { Value }\end{array}$ & P-value \\
\hline Grade I & 11.48 & 8.4 & 8.12 & 28 & & \\
\hline Grade II & 10.25 & 7.5 & 7.25 & 25 & & \\
\hline Grade III & 6.56 & 4.8 & 4.64 & 16 & 31.827 & 20.09 \\
\hline Grade IV & 7.38 & 5.4 & 5.22 & 18 & & \\
\hline Grade V & 5.33 & 3.9 & 3.77 & 13 & & \\
\hline Total & 41 & 30 & 29 & 100 & & \\
\hline
\end{tabular}

Table-II. Relation of grades of ulcer and types of amputation, $n=100$

Expected frequencies are shown and chi square distribution was used. The critical value is less than chi square value and $p$-value is less than $0.05 \%$. So the null hypothesis $\mathrm{H}_{0}$; the role of ulcer grading has no significant role as a predictor level of amputation in diabetic foot ulcer patients was rejected.

\section{DISCUSSION}

According to the consensus guidelines of foot care, all patients having diabetic foot have better treatment outcomes if treated by multidisciplinary treatment teams. However, despite the establishment of consensus guidelines, many patients who afterwards undergo amputations do not obtain any multidisciplinary treatment. Amputation rates could be reduced when the first symptoms of diabetes related foot complications appear and there is early referral of patients to the multidisciplinary foot team. So, more efforts put to ensure that patients who are at risk of LEA (Lower extremity amputation) get effective foot care in time as soon as a foot ulcer is observed, preferably within first two weeks (Grade 0 is a minor risk factor which is managed as conservatively and it is not used as a predictor for amputation). These measures would probably lead to prevention of amputations in diabetic patients.

The aim of primary amputation is to provide best functional outcome, achieve rapid and successful mobility with an artificial limb. ${ }^{11}$ Peripheral arterial disease is a common large vessel complication of diabetes and baseline predictor of foot ulceration, leading to occlusion of the major vessels supplying the extremities. ${ }^{12,13}$ The patients who were amputated in this study were predominantly male, our finding are consistent with studies. ${ }^{14,15}$ Different studies indicated foot ulcer and amputation highly significant for male gender, due to smoking habits and hypertension. ${ }^{16}$ Aspect reveals that females may have more efficient healing of wounds due to the wound healing properties of estrogen receptors, whereas androgens are linked to be unfavorable to wound healing. ${ }^{17}$ This correlates well to previous findings indicating that male sex is a risk factor being more commonly affected by foot ulcers. ${ }^{18}$

Female patients with diabetes were significantly five year older when amputated compared to male diabetic patients. Mean age of female diabetic patients in Korea is 5 years higher (49.3 to 50.6) than in male diabetic patients. ${ }^{19}$ However, the study performed by Ferrani et a ${ }^{20}$ establish no meaningful association between gender and amputation. Considering these differences, it becomes necessary to carry out more research in this area. Bowling et $\mathrm{al}^{21}$ demonstrated that, ulceration results due to combination of 
different components that together lead to tissue breakdown. Frequently occurring of foot ulcers are due to peripheral neuropathy, vascular diseases, foot deformity or trauma. Furthermore, an increase of one point in the Wagner ulcer classification criteria corresponded to a $65 \%$ increase in the risk of amputation. ${ }^{22}$

Our study showed a high grade of ulcer severity (Grade from 3 to 5) leads to increase in the risk of major amputation. This result was well-matched with the clinical observation that a more extensive the wound was, more extensive the surgical management, such as amputation would be. Sun et $\mathrm{al}^{23}$ showed that a higher the grade of Wagner classification the stronger indication of amputation, similar to our study. Wagner grade 3 and 4 lesions are indeed associated with higher risk of amputation of the lower limbs in the literature. ${ }^{24}$ Results by Jeon et al ${ }^{25}$ showed that, all five classifications have been strongly associated with the overall occurrence of Lower extremity ulcers amputation. In summary, diabetic foot ulcers pose a significant risk for amputation, specially complicated deep ulcer. Further research is needed to evaluate other factors which also contribute to amputation.

\section{CONCLUSION}

The range of complications among diabetic foot is a major complication. The best outcome of diabetic foot can be treated by multidisciplinary team. Wagner classification of diabetic foot ulcer high grade is associated with increased risk along with high level of foot amputation. The higher the grade of ulcer, the higher risk of major amputation of limb.

\section{Copyright@ 11 May, 2020.}

\section{REFERENCES}

1. World Health Organization. Global Report on Diabetes. Isbn. 2016; 83.

2. Sicree BR, Shaw J, Zimmet P. The global burden: Diabetes and impaired glucose tolerance. Diabetes Atlas. 2011; 27:15-20.

3. Hopkins RB, Burke N, Harlock J, Jegathisawaran J, Goeree R. Economic burden of illness associated with diabetic foot ulcers in Canada. BMC Health Serv Res. 2015; 15:13.
4. Rice JB, Desai U, Cummings AKG, Birnbaum HG, Skornicki M, Parsons NB. Burden of diabetic foot ulcers for medicare and private insurers. Diabetes Care. 2014; 37(3):651-8.

5. Suh HS, Hong JP. Diabetic foot ulcer. J Korean Med Assoc. 2015; 58(9):795-800.

6. Pemayun TGD, Naibaho RM, Novitasari D, Amin N, Minuljo TT. Risk factors for lower extremity amputation in patients with diabetic foot ulcers: A hospital-based case-control study. Diabet Foot Ankle. 2015; 6:296-9.

7. Pickwell K, Siersma V, Kars M, Apelqvist J, Bakker K, Edmonds $\mathrm{M}$, et al. Predictors of lower-extremity amputation in patients with an infected diabetic foot ulcer. Diabetes Care. 2015; 38(5):852-7.

8. Ashraf MN, Khalil-ur-Rehman, Malik KI, Iqbal GS. J Ayub Med Coll Abbottabad. 2011; 23(1):122-4.

9. Kumar S, Arava S, M. P, S. G, B. CG, M. NK. Diabetic ulcer severity score: Clinical validation and outcome. Int Surg J. 2016; 3(3):1606-1610.

10. Huang Y, Xie T, Cao Y, Wu M, Yu L, Lu S, et al. Comparison of two classification systems in predicting the outcome of diabetic foot ulcers: The Wagner grade and the Saint Elian Wound score systems. Wound Repair Regen. 2015; 23(3):379-85.

11. Attinger $\mathrm{CE}$, Brown BJ. Amputation and ambulation in diabetic patients: Function is the goal. Diabetes/ Metabolism Research and Reviews. 2012. 28(1):93-6.

12. Forsythe RO, Brownrigg J, Hinchliffe RJ. Peripheral arterial disease and revascularization of the diabetic foot. Diabetes, Obesity and Metabolism. 2015. 17(5):435-44.

13. Fraser K, Raju I. Anaesthesia for lower limb revascularization surgery. BJA Educ. 2015; 15(5):225230.

14. Borne A, Porter A, Recicar J, Maxson T, Montgomery C. Pediatric Traumatic Amputations in the United States: A 5-Year Review. Journal of Pediatric Orthopaedics. 2017. 37(2):104-107.

15. Salminger $S$, Roche AD, Hruby LA, Sturma A, Riedl $\mathrm{O}$, Bergmeister KD, et al. Prosthetic reconstruction to restore function in transcarpal amputees. J Plast Reconstr Aesthetic Surg. 2016; 69(3):305-310.

16. Parisi MCR, Neto AM, Menezes FH, Gomes MB, Teixeira RM, De Oliveira JEP, et al. Baseline characteristics and risk factors for ulcer, amputation and severe neuropathy in diabetic foot at risk: The BRAZUPA study. Diabetol Metab Syndr. 2016; 8:25. 
17. Jonasson JM, Ye W, Sparén P, Apelqvist J, Nyrén O, Brismar K. Risks of nontraumatic lower-extremity amputations in patients with type 1 diabetes: $A$ population-based cohort study in Sweden. Diabetes Care. 2008; $31(8): 1536-40$.

18. Al-Rubeaan K, AIDerwish M, OuiziS, YoussefAM, Subhani $\mathrm{SN}$, Ibrahim HM, et al. Diabetic foot complications and their risk factors from a large retrospective cohort study. PLoS One. 2015; 10(5):756-760.

19. Noh J. The diabetes epidemic in Korea. Endocrinology and Metabolism. 2016; 31(3):349-353.

20. Ferranti KM, Osler TM, Duffy RP, Stanley AC, Bertges DJ. Association between gender and outcomes of lower extremity peripheral vascular interventions. J Vasc Surg. 2015; 62(4):990-7.

21. Bowling FL, Rashid ST, Boulton AJM. Preventing and treating foot complications associated with diabetes mellitus. Nature Reviews Endocrinology. 2015; 11(10):606-16.
22. Verrone Quilici MT, Del Fiol FDS, Franzin Vieira AE, Toledo MI. Risk factors for foot amputation in patients hospitalized for diabetic foot infection. J Diabetes Res. 2016; 1-8.

23. Sun JH, Tsai JS, Huang $\mathrm{CH}$, Lin $\mathrm{CH}$, Yang HM, Chan YS, et al. Risk factors for lower extremity amputation in diabetic foot disease categorized by Wagner classification. Diabetes Res Clin Pract. 2012; 95(3):35863.

24. Mills JL, Conte MS, Armstrong DG, Pomposelli FB, Schanzer A, Sidawy AN, et al. The society for vascular surgery lower extremity threatened limb classification system: Risk stratification based on Wound, Ischemia, and foot Infection (WIfl). J Vasc Surg. 2014;59(1):220-34.

25. Jeon BJ, Choi HJ, Kang JS, Tak MS, Park ES. Comparison of five systems of classification of diabetic foot ulcers and predictive factors for amputation. Int Wound J. 2017; 14(3):537-545.

\begin{tabular}{|c|c|c|c|}
\hline \multicolumn{4}{|c|}{ AUTHORSHIP AND CONTRIBUTION DECLARATION } \\
\hline Sr. \# & Author(s) Full Name & Contribution to the paper & Author(s) Signature \\
\hline 1 & Khalil ur Rehman & $\begin{array}{l}\text { Conception, design, Synthesis and } \\
\text { Planning of the research, Active } \\
\text { participation in data collection and } \\
\text { management, drafting of article. }\end{array}$ & \\
\hline 2 & M. Naeem Ashraf & $\begin{array}{l}\text { Participation in active methodology, } \\
\text { Assembly of data, Statistical } \\
\text { expertise. }\end{array}$ & \\
\hline 3 & Naveed Arshad & $\begin{array}{l}\text { Analysis and interpretation of the } \\
\text { data and drafting. }\end{array}$ & \\
\hline 4 & Saima Mir & $\begin{array}{l}\text { Participation in statistical analysis } \\
\text { and discussion. }\end{array}$ & \\
\hline 5 & Nadeem Pasha & Active participation in discussion. & \\
\hline
\end{tabular}

